\title{
A CRISE DE LEGITIMIDADE DO SISTEMA ELEITORAL
}

\author{
GIL DE ARAÚJO CORRÊA \\ MILTON LAMENHA DE SIQUEIRA
}




\section{A CRISE DE LEGITIMIDADE DO SISTEMA ELEITORAL}

\section{GIL DE ARAÚJO CORRÊA $A^{1}$ MILTON LAMENHA DE SIQUEIRA ${ }^{2}$}

\section{RESUMO}

Este artigo procura fazer uma reflexão acerca das características do regime democrático e suas conseqüências para a legitimação da forma de governo, elaborando uma crítica à legitimidade do sistema eleitoral brasileiro e apresentando possíveis soluções para essa crise de legitimidade.

\section{ABSTRACT}

This article expects to make a reflexión about the charceteristics - of the democratic regime and its consequences for the legitimation of the government way, elaborating a criticism to the legitimation of the brasilian election system and presenting possible solutions for that legitimacy crisis.

\footnotetext{
${ }^{1}$ Pós-graduando em Direito Constitucional pela Universidade do Tocantins-UNITINS e Juiz de Direito titular da $1^{\text {a }}$ Vara Criminal de Palmas-TO

${ }^{2}$ Pós-graduando em Direito Constitucional pela Universidade do Tocantins-UNITINS e Juiz de Direito titular da $1^{\text {a }}$ Vara Criminal de Pedro Afonso-TO
} 


\section{INTRODUÇÃo}

A cada crise política porque passa o País, verificamos uma quase unanimidade de analistas e gente do povo apontar o acusatório indicador para a nossa forma de Governo, Democrático.

Com efeito, com muita rapidez passamos a falar mal dos políticos detentores de mandato, desdenhando seu papel na sociedade, admoestando sua conduta pública e privada e lamentando sua fidelidade a interesses que, acreditamos, não são os nossos, os do povo brasileiro. De imediato elocubramos quem teria financiado a campanha daqueles cujos posicionamentos não compartilhamos nem abonamos com o nosso voto.

A classe política brasileira está entre as mais desprestigiadas das classes do País, sendo esse um fato público e notório, ratificado pelas inúmeras pesquisas de opinião que, há mais tempo do que seria razoável, vêm, invariavelmente, indicando a insatisfação do eleitor com seus senadores, deputados, vereadores e chefes de poder executivo.

Todavia, a Democracia brasileira, desde 1989, vem elegendo, de forma plena, em eleições livres, todos os seus representantes, organizados em partidos políticos, por meio de voto direto e secreto, vale dizer que, em tese, não seria de se observar a crise que apontamos acima, posto que a Constituição, efetivamente, elaborou um sistema democrático garantindo ao cidadão o pleno acesso aos mandatos e ao sufrágio. Por que, então, o sistema não funciona? Ou, por outra, por que o sistema recebe tantas críticas?

0 presente trabalho pretende, sem qualquer intenção de esgotar o assunto, fazer uma reflexão sobre os fundamentos do Regime Democrático sob o prisma da Legitimidade dos governos e parlamentares eleitos e indicar, se possível, uma saída para essa crise de legitimidade pela qual passa nosso atual sistema de Governo. 


\section{FUNDAMENTO DO REGIME DEMOCRÁTICO}

De início é preciso gizar que a Democracia não é um valor universal, uma idéia inata de evolução. Menos ainda o é a democracia burguesa ou liberal. Não podemos esquecer que até a segunda metade do séc. XX, a democracia sequer era tida como Direito do Homem, tal como pensado na tradição iluminista e burguesa.

Ainda hoje a Democracia não empolga na maior parte do nosso planeta. Mesmo quando ela é reconhecida como uma forma de república mais civilizada e isonômica, ainda assim suscita dúvidas ou desconfianças.

Não se fará aqui qualquer discussão sobre se essa é a mais adequada forma de governo da República. Simplesmente partiremos da premissa de que esse regime de governo é o mais adequado à República e aquele que mais respeita e prestigia o povo na adoção das decisões políticas. Façamos, todavia, um escorço do conceito na linha do tempo.

Com a ancila do Dicionário de Política ${ }^{3}$, no qual Norberto Bobbio assina o verbete Democracia, encontramos três grandes tradições do pensamento político no que tange aos governos. A tradição clássica ou aristotélica; a teoria medieval e, por fim a teoria moderna assentada em Maquiavel.

\subsection{FORMAS DE GOVERNO NA ANTIGÜIDADE}

A tradição aristotélica é aquela que separa as formas de governo em monarquia, aristocracia e democracia e na qual esta se distingue das demais por ser o governo de todos os cidadãos em contraposição à monarquia, governo de um só, e à aristocracia, que é o governo de poucos. Mesmo nessa concepção a democracia não é vista como um

\footnotetext{
${ }^{3}$ Dicionário de Política, Norberto Bobbio, Niccola Matteucci e Ginafranco Pasquino, LGE Editora e Editora UNB, tradução de Carmen C. Varriale, Gaetano Lo Mônaco, João Ferreira, Luís Guerreiro Pinto Cacais e Renzo Dini, Brasília, 12ª edição, 2004, p.319 e ss.
} 
valor universal positivo, na medida em que consistiria no governo dos iletrados, despreparados. ${ }^{4}$

\subsection{FORMAS DE GOVERNO NA IDADE MÉDIA}

A teoria medieval, de origem romana, se assenta no conceito de soberania popular no qual o poder supremo se origina no povo, e se torna representativo, ou do príncipe e é transmitido por delegação do superior ao inferior. Os juristas medievais, calcados no Digesto, especialmente em Ulpiano ${ }^{5}$, para quem o príncipe tinha autoridade porque o povo lha conferia, e em Juliano ${ }^{6}$, que afirmava, a propósito do costume como fonte de direito, que o povo cria o direito não apenas através do voto, dando vida às leis, mas também dando vida aos costumes, demonstravam que qualquer que fosse o detentor do poder soberano, sua fonte originária seria sempre o povo, abrindo caminho para a dicotomia entre titularidade e exercício do poder, concluindo que o povo ao aceitar o soberano não estava transferindo essa soberania a ele, senão que apenas a delegando. Ou seja, onde o povo transferiu a outrem o poder de fazer leis, sempre conservara o poder de criar direito através da tradição.

\subsection{FORMAS DE GOVERNO NA IDADE MODERNA}

Finalmente, a teoria moderna, conhecida como Teoria de Maquiavel, nascida com o Estado moderno, segundo a qual as formas de Governo seriam duas, a saber, a Monarquia e a República, sendo a Democracia, na acepção grega, apenas uma forma de governo da República, sendo a outra a aristocracia. Nesta concepção, a Democracia não se confunde exatamente com a República, posto que pode haver repúblicas aristocráticas, como as italianas do medievo.

\footnotetext{
${ }^{4}$ Idem, p. $320,1^{\mathrm{a}} \mathrm{col}$.

${ }^{5}$ Idem, p. 321, $1^{\text {a }}$ col.

${ }^{6}$ ibidem
} 
Entretanto, Rousseau, no seu Contrato Social ${ }^{7}$, faz confluírem ambas as concepções, rectius, da Democracia e da República, na clássica doutrina da soberania popular, a quem compete, através da formação de uma vontade geral inalienável, indivisível e infalível, o poder de fazer as leis. A doutrina contratualista do Estado se funda no consenso e na participação de todos na produção das leis.

De mister registrar, ainda, que a democracia tanto pode ser o sistema de governo de uma república liberal quanto de uma república socialista.

\subsection{LIBERALISMO}

No liberalismo, o ponto de partida foi a distinção levada a cabo por Benjamin Constant8 entre a liberdade dos antigos comparada com a liberdade dos modernos. A liberdade dos modernos é a liberdade individual frente ao Estado e a dos antigos seria aquela entendida como participação direta na formação das leis através do corpo político, cuja máxima expressão está na assembléia dos cidadãos. Identificada a Democracia, para esse pensador - e com ele Tocqueville e Sturat Mill — como a Democracia Direta, foi tomando forma a idéia de que em Estados onde se garantisse um mínimo de liberdades civis e políticas, não seria produtivo e, pelo contrário, até danoso, manter a democracia direta. Engendrou-se, então, a concepção da Democracia Representativa ou Parlamentar, onde o dever de fazer leis seria retirado da totalidade do povo reunido em assembléia e transferido para um corpo reduzido de representantes eleitos pela totalidade dos cidadãos a quem se reconhecia os direitos políticos. A participação do cidadão nas decisões de governo, num Estado liberal, se restringiria à participação desse cidadão da eleição de um representante que decidiria por ele. Esse direito de eleger estaria inserido

\footnotetext{
${ }^{7}$ Idem, p. 323, 1․ㅡ. $\mathrm{col}$.

${ }^{8}$ Ibidem, p. 323, 2 ${ }^{\text {a }}$ col.
} 
no rol das liberdades civis embora delas se diferenciasse, porque as liberdades civis são meras faculdades de fazer ou não fazer frente ao Estado, onde o cidadão pode recusar-se a agir de determinada forma, sendo, portanto, liberdades negativas, enquanto que o reconhecimento de direitos políticos são liberdades positivas, na medida em que é reconhecida ao cidadão uma capacidade jurídica que lhe permitirá influir na tomada de decisões do Estado. Decorre daí que não pode haver Estado liberal onde não se reconhece o princípio da soberania popular, nem onde não forem reconhecidas liberdades capazes de assegurar uma participação política do cidadão livre e desembaraçada de pressões. É interessante notar que o Estado liberal, no início, não reconhecia a todos os nacionais os direitos políticos, como no Brasil até as três primeiras décadas do séc. XX, e que, de lá para cá, o desenvolvimento da Democracia vem se fazendo no sentido quantitativo, de expandir o corpo eleitoral.

\subsection{SOCIALISMO}

Tomando-se como certo que o objetivo final da Democracia é " a erradicação do abuso do poder, seja ele político ou econômico, a crítica socialista à Democracia representativa é de que houve um deslocamento do poder dos órgãos tradicionais do Estado para a grande empresa e, por isso, o controle que o cidadão exerceria pelos meios políticos tradicionais não são mais suficientes para obstar àqueles abusos, deixando para o trabalhador da fábrica, e não mais para o cidadão, a tarefa de exercer o controle por meio dos comitês de fábrica que seriam, no seu conjunto, uma federação de conselhos de trabalhadores.

Temos, então, que o liberalismo critica a democracia direta e o socialismo impugna a democracia representativa. Essa crítica é eminente ideológica, calcada na forma de se chegar aos fins últimos de cada uma delas. Entretanto, no fim do séc. XIX, surgiu uma teoria que pretendeu deixar de lado as ideologias e se assentar nos fatos, cientificamente. Seus defensores - Ludwig Gumplowicz, Gaetano Mosca 
e Vilfredo Pareto ${ }^{9}$ - foram os teóricos das "elites governamentais" e criaram a Teoria do Elitismo.

\subsection{ELITISMO}

Essa teoria é o corolário histórico do desenvolvimento das formas de Governo ao afirmar que em qualquer época da história humana, sob qualquer regime de governo, é sempre um pequeno grupo de pessoas que exerce efetivamente o poder, eles chamam esse pequeno grupo de "elite política". No fundo, só existe uma forma de Governo, a oligárquica.

Não quer isso dizer, porém, que todas as formas de governo sejam iguais. Elas dissentem, mas não em razão do número dos que governam (um, poucos ou muitos), porque esse número será sempre pequeno, mas na forma de composição dessa elite. Os governos se diferenciam pelo modo como essa classe política se forma, se reproduz, se alterna, organiza e exerce o poder.

Segundo Norberto Bobbio, citando Mosca ${ }^{10}$, há governos em que a classe política se forma com a transferência hereditária e outros que se alimentam das classes inferiores para constituir a classe política; há as classes políticas que exercem o poder sem controle e aquelas que são controladas a partir de baixo.

Desta forma, Democracia não se resume mais em realizar o bem comum de acordo com a vontade geral do povo, ainda que este seja indeterminado. Há necessidade de se conceituar a Democracia por aferição de vários indicadores.

Bobbio cita Joseph Schumpeter para afirmar que existe Democracia onde há vários grupos em concorrência pela conquista do poder através de uma luta que tem por objeto o voto popular. Mas ainda isso não é o bastante. É preciso que essa disputa pelo voto popular deve compreender pelo menos três

\footnotetext{
${ }^{9}$ Idem, p. 325, $2^{\text {a }}$ col.

${ }^{10}$ Opus Cit. p. $326,1^{\text {a }} \mathrm{col}$.
} 
pontos: o recrutamento, a extensão e a fonte do poder da classe política.

Eis o que diz Bobbio, verbis:

\begin{abstract}
"Com respeito ao recrutamento, uma classe política pode chamar-se democrática quando seu pessoal é escolhido através de uma competição eleitoral livre e não através de transmissão hereditária ou de cooptação. Com respeito à extensão, quando o pessoal de uma classe política é tão numeroso que se divide, de maneira estável, em classe política de Governo e classe política de oposição e consegue cobrir a área do Governo central e do Governo local em suas diversas articulações e não é, por outra parte, constituído de um grupo tão pequeno e fechado que dirige um país inteiro através de comissários ou funcionários dependentes. Com respeito à fonte do poder, quando este é exercido por uma classe política representativa, com base numa delegação periodicamente renovável e fundada sobre uma declaração de confiança, e no âmbito de regras estabelecidas (constituição) e não em virtude de dotes carismáticos do chefe ou como consequência da tomada violenta do poder (golpe de Estado, revolta militar, revolução, etc.)". (Dicionário de Política, p. 326, $1^{\text {ạ }}$ col., in fine)
\end{abstract}

Democracia, portanto, se considera o sistema de Governo que não tem uma definição, mas um conceito. É um método para um sistema de Governo e de tomada de decisões políticas que se caracteriza entre outras coisas por ${ }^{11}$ :

1) o órgão político máximo, a quem é assinalada a função legislativa, deve ser composto de membros direta ou indiretamente eleitos pelo povo, em eleições de primeiro e segundo grau;

2) junto do supremo órgão legislativo deverá haver outras instituições com dirigentes eleitos, como os órgãos da administração local ou o chefe de Estado (tal como acontece nas repúblicas);

\footnotetext{
${ }^{11}$ Opus cit, p. 327.
} 
3) todos os cidadãos que tenham atingido a maioridade, sem distinção de raça, de religião, de censo e possivelmente sexo, devem ser eleitores;

4) todos os eleitores devem ter voto igual;

5) todos os eleitores devem ser livres em votar segundo a própria opinião formada o mais livremente possível, isto é, numa disputa livre de partidos políticos que lutam por uma representação nacional;

6) devem ser livres também no sentido em que devem ser postos em condição de ter reais alternativas (o que exclui como democrática qualquer eleição de lista única ou bloqueada);

7) tanto para as eleições dos representantes como para as decisões do órgão político supremo vale o princípio da maioria numérica, se bem que podem ser estabelecidas várias formas de maioria segundo critérios de oportunidade não definidos de uma vez para sempre;

8) nenhuma decisão tomada pela maioria deve limitar os direitos da minoria, de um modo especial o direito de tornar-se maioria, em paridade de condições;

9) o órgão do Governo deve gozar de confiança do Parlamento ou do chefe do poder executivo, por sua vez eleito pelo povo.

Saliente-se que esse conjunto de indicativos, que uma república deve observar se quiser democrática, somente estabelece como as decisões políticas devem ser tomadas e não o conteúdo dessas decisões. Significa dizer que qualquer decisão política tomada com observância desses requisitos é uma decisão democrática, exceto, talvez, se quiser destruir as próprias cláusulas pétreas do sistema.

Com que, então, de um modo geral, para o que nos interessa no presente trabalho, qualquer que seja a teoria a respeito da democracia que adotemos, todas elas aludem, quase sem discrepância, à pulverização do poder na formação da vontade geral, ainda que se reconheça que sempre esse poder soberano é exercido por uma minoria. É dizer que as decisões estatais se fundem sempre, na democracia, num binômio que poderíamos estabelecer como igualdade e legiti- 
midade. 0 sistema se legitima ao reconhecer no povo a sede do poder soberano, mas não só.

A democracia é o sistema de governo que calca sua legitimidade, para a tomada das decisões políticas, na participação igual de todos na construção dessa vontade. Essa participação pode ser direta ou indireta, mas em qualquer de suas formas pressupõe que todos os cidadãos dela participaram, seja por meio de voto direto na decisão política que mais lhe interesse, seja por meio da eleição de representantes. Em qualquer dos casos, porém, o que deve se refletir na decisão política é a decisão dos cidadãos, dos eleitores, sob pena de se retirar da decisão tomada a legitimidade que garante ao órgão executivo seu desempenho e a estabilidade social.

\section{IGUALDADE}

Com isso chegamos ao princípio sede, à idéia original, por trás do sistema democrático que é a idéia de que "todos somos iguais". "Todos somos iguais perante a lei", na tradição liberal. Desde Sócrates que a humanidade sabe que o Estado nasceu para equalizar as desigualdades entre os homens. Nivelar o fraco e o forte, proteger aquele deste. Só que, inicialmente, ainda não se reconhecia a todos a capacidade de ser sujeito de direitos. Com a evolução do pensamento ocidental passou-se de uma "casta" de cidadãos, geralmente proprietários, para abranger todo o povo, vale dizer que os direitos políticos, que inicialmente eram reconhecidos somente aos pares da polis, passou a abranger gradualmente, até o clímax da Revolução Francesa aqui excluída a Revolução Americana porque manteve a iniqüidade da escravidão - todo o membro do povo.

Todavia, não podemos olvidar que, embora a Revolução Francesa tenha sido um marco extraordinário na História da Humanidade ao rechaçar a qualificação ou desqualificação do homem pelo nascimento, foi ela protagonizada pela burguesia, pela parte da sociedade que não tinha nascimento para participar das decisões, mas tinha posses, 
assim se desigualando do grosso dos cidadãos até então composto de servos.

Daí porque, extinta a aristocracia e o absolutismo, remanesceram, ainda, formas de desigualdade que se refletiam quer no nível de instrução, quer nas posses dos cidadãos libertados do jugo absolutista.

Havia, por certo, a igualdade perante a lei, mas mesmo esse primado não representava exatamente a igualdade entre todos os cidadãos.

Além disso, a Revolução Francesa deu ao mundo o slogan "Liberdade, Igualdade e Fraternidade" a indicar que ela objetivara e obtivera simultaneamente essas três afecções ao status de cidadão o que, obviamente, não ocorreu.

Com efeito, bem ao modo burguês, deu-se ênfase, neste trinômio, à "liberdade" que para o liberal de então não só significava o laissez-faire, mas, principalmente, o laissez-passer, ou seja, não só a liberdade de iniciativa, porém, principalmente, a liberdade de explorar o próximo. Liberdade para ser o "lobo do homem". Liberdade para ignorar a Igualdade.

Hodiernamente, podemos constatar que a igualdade é um atributo da liberdade. A liberdade que não compreenda, como condição sine qua non, a igualdade entre os seres humanos não pode ser assim entendida.

É, na verdade, a igualdade que qualifica o regime democrático, pois, a liberdade no sentido liberal em que é usualmente compreendida não é suficiente para assinalar como democrático um sistema de governo.

Como bem explicita José Afonso da Silva ${ }^{12}$, verbis;

"O direito de igualdade não tem merecido tantos discursos

${ }^{12}$ In Curso de Direito Constitucional Positivo, Editora Malheiros, São Paulo, $19^{\mathrm{a}}$ edição, 2001, p.214. 
como a liberdade. As discussões, os debates doutrinários e até as lutas em torno desta obnubilaram aquela. É que a igualdade constitui o signo fundamental da democracia. Não admite os privilégios e distinções que um regime simplesmente liberal consagra. Por isso é que a burguesia, cônscia de seu privilégio de classe, jamais postulou um regime de igualdade tanto quanto reivindicara o de liberdade. É que um regime de igualdade contraria seus interesses e dá à liberdade sentido material que não se harmoniza com o domínio de classe em que assenta a democracia liberal burguesa."

De fato, a mera "igualdade perante a lei" na realidade não tem sentido material algum, pois a lei reproduz o domínio de classe na democracia liberal burguesa e renova e perpetua as desigualdades flagrantes existentes nessas sociedades.

0 debate sobre a igualdade permeou o período áureo do Iluminismo tendo sobre ele se debruçado, entre outros, Locke e Rousseau. Nesse período ganhou força a idéia de uma igualdade inata do homem, tal como existente no estado de natureza. Uma igualdade absoluta, como queria Locke, ou reconhecendo-se algum tipo de desigualdade, como pensava Rousseau, como aquela decorrente das diferenças físicas ou decorrentes de estatutos consentidos pelos próprios homens que ele chamava de desigualdade moral ou política.

De nossa parte, e no que interessa para a presente reflexão, entendemos que os homens, de fato, nascem desiguais, na medida em que nascem, uns altos outros baixos, uns fortes outros franzinos, uns machos outros fêmeas. Essa é uma desigualdade natural que, antes do advento do Estado, serviu para definir a dominação do forte sobre o fraco, por exemplo.

Essa desigualdade não será a desigualdade que marcará o Estado Democrático, haja vista que, seguindo a concepção socrática já exposta acima, o próprio Estado, em seu nascedouro, a procurou resolver ao equalizar as relações entre os cidadãos. Já a desigualdade consentida, mencionada por Rousseau, decorre de convenção, convenção 
que, no limite do raciocínio, estatuiu aquele Estado que reconhece privilégios aos mais nobres ou poderosos.

Evidentemente que a igualdade - ou o reconhecimento da desigualdade - não está contido nessas concepções físicas, no reconhecimento, de todo palmar, de que somos uns brancos outros pretos, baixos e altos, gordos ou magros, feios ou bonitos, uns brilhantes outros medíocres. E muito menos naqueles estatutos que reconhecem uma desigualdade política.

Conforme Charles Perelman ${ }^{13}$, verbis:

\begin{abstract}
“(....) não se aspira uma igualdade que frustre e desbaste as desigualdades que semeiam a riqueza humana da sociedade plural, nem se deseja uma desigualdade tão grande e injusta que impeça o homem de ser digno em sua existência e feliz em seu destino. 0 que se quer é a igualdade jurídica que embase a realização de todas as desigualdade humanas e as faça suprimento ético de valores poéticos que o homem possa desenvolver. As desigualdades naturais são saudáveis, como são doentes aquelas sociais e econômicas, que não deixam alternativas de caminhos singulares a cada ser humano único."
\end{abstract}

Nossa igualdade consiste em que existimos e vivemos em sociedade e devemos buscar a melhor maneira de disciplinar esse convívio, respeitando a todos de igual maneira e reconhecendo, também a todos, direito de participar da vida comum e das decisões políticas que a influenciam.

Em outras palavras, não basta, para um regime verdadeiramente democrático, uma igualdade meramente formal, "perante a lei", sem um conteúdo que nivele todos os cidadãos. Exige-se um conceito mais amplo da Igualdade que contemple aquele sentido material que queremos dar. Esse conceito é o da isonomia.

\footnotetext{
${ }^{13}$ Apud José Afonso da Silva, opus cit. p. 216.
} 


\section{Gilmar Ferreira Mendes ${ }^{14}$ afirma que esse princípio, verbis:}

“(....) significa em resumo tratar igualmente os iguais e desigualmente os desiguais, na medida de sua desigualdade. Como, por outro lado, no texto da nossa Constituição, esse princípio é enunciado com referência à lei - todos são iguais perante a lei -, alguns juristas construíram uma diferença, porque a consideram importante, entre igualdade na lei e a igualdade diante da lei, a primeira tendo por destinatário precípuo o legislador, a quem seria vedado valer-se da lei para fazer discriminações entre pessoas que mereçam idêntico tratamento; a segunda dirigida principalmente aos intérpretes/aplicadores da lei, impedir-lhes-ia de concretizar enunciados jurídicos dando tratamento distinto a quem a lei encarou como iguais."

Em outras palavras, a isonomia reconhece um grau de desigualdade entre os cidadãos e objetiva relativizar essa desigualdade por meio de tratamento desigual àqueles que são desiguais e na medida dessa mesma desigualdade. Vale dizer, é dar um sentido material, concreto, à igualdade constitucionalmente garantida aceitando que, apesar de sermos iguais ao existirmos e convivermos, nosso lugar na sociedade não é igual.

Com que, então, nos Estados Democráticos de Direito, a igualdade é obtida por meio da isonomia, que trata desigualmente os desiguais e, com isso, permite a participação de todos, de igual maneira, na formação da vontade política que decidirá as questões fundamentais da administração do Estado. Isso se dá pelo pluralismo político.

Numa sociedade multi-facetada como a sociedade moderna, muitos são os interesses dos cidadãos e múltiplas as formas de gerir o bem público. Os cidadãos, então, se organizam conforme sua afinidade de pensamento quanto aos critérios de tomada de decisão política e quanto aos objetivos do Estado.

\footnotetext{
${ }^{14}$ In Curso de Direito Constitucional, em co-autoria com Inocência Mártires Coelho e Paulo Gustavo Gonet Branco, Editora Saraiva, São Paulo, 2007, p. 147.
} 
Há muitas formas de entidades que organizam os cidadãos, tais como sindicatos, associações e partidos políticos, mas apenas a esses últimos é reconhecido o direito de participar do processo eleitoral com vistas à assunção de cargos públicos que gestão do Estado.

A existência dos partidos políticos sinaliza a existência no Estado da garantia da diversidade, garantindo-se não só o direito de pensar ideologicamente de forma diferente, mas, mais importante, de ser diferente em quaisquer áreas, âmbitos ou expressões da convivência humana.

\subsection{IGUALDADE E DEMOCRACIA REPRESENTATIVA}

Voltando nossos olhos para os partidos políticos vemos que têm eles a função precípua de reunir em torno de uma agremiação pessoas que pensam de forma similar - muitas vezes igual - em relação ao Estado e à sociedade e à forma de tomada das decisões.

São, os partidos, possíveis na democracia direta e imprescindíveis na democracia indireta, sistema no qual os cidadãos, como já vimos, elegem seus representantes para participar do processo de tomada das decisões políticas.

Portanto, numa democracia representativa a igualdade do cidadão é obtida com a liberdade de filiação partidária, o que lhe dá o direito de candidatar-se para integrar os órgãos de tomada de decisão e, também, pela possibilidade de eleger aquele que melhor represente sua forma de entender o Estado, sua administração e quais as prioridades que devem ser levadas em conta no processo de tomada de decisões políticas.

Mas é certo que somente essa igualdade - de eleger-se e de votar - não basta para legitimar o regime democrático. Além da igualdade, pois, em que consistiria a legitimidade do regime? 


\title{
4. LEGITIMIDADE
}

Viemos de dizer que numa democracia burguesa não é o princípio da igualdade que é buscado, pois esse princípio impõe um nivelamento que a sociedade burguesa não quer. É o princípio da liberdade, inclusive da liberdade de explorar o próximo que predomina.

Assim, é possível que um regime democrático seja legal, posto que embasado em leis, mas não seja legítimo, quando os representantes do povo detém o poder de forma injusta.

Como bem explana José Afonso da Silva ${ }^{15}$, verbis:

\begin{abstract}
"Por aí se vê que legitimidade e legalidade nem sempre se confundem. Lembra bem D’Entrève: 'Legalidade e legitimidade cessam de identificar-se no momento em que se admite que uma ordem pode ser legal mas injusta.' Propõe, por isso, a recuperação do liame entre legalidade e legitimidade, sob bases diferentes, a partir do abandono da noção puramente formal da legalidade, definindo-a como 'a realização das condições necessárias para o desenvolvimento da dignidade humana', como quer nossa Constituição (art.1ำ III), pois o 'princípio da legalidade não exige somente que as regras e as decisões que compõem o sistema sejam formalmente corretas'. Ele exige que elas sejam conforme certos valores, a valores necessários 'à existência de uma sociedade livre', tarefa exigida expressamente do Estado Brasileiro (art. $3^{\circ}$, I).
\end{abstract}

Vale dizer, o regime democrático não se legitima somente com as decisões políticas sendo tomadas por representantes do povo. É preciso que esses representantes sejam eleitos em certames limpos, que não gerem distorções na representação, e que eles, eleitos, decidam conforme certos valores, valores éticos e morais amplamente aceitos pela sociedade.

\footnotetext{
${ }^{15}$ Opus cit. p. 427.
} 


\section{O SISTEMA BRASILEIRO}

O Estado brasileiro está constituído, segundo sua Carta Fundamental, num Estado Democrático de Direito. É possível verificar que ele atende à quase totalidade do rol de Norberto Bobbio que expusemos no item 2.4 .

Dizemos a quase totalidade porque é evidente que a crise de legitimidade apontada na introdução desse artigo impõe que se afirme que as tomadas de decisão adotadas pelos representantes do povo não está em sintonia com os valores que esse povo tem. Só isso explica o desprestígio da classe política e o escárnio que recebe do público eleitor.

0 sistema brasileiro permite a livre associação de pessoas em sindicatos, associações e partidos políticos. Todavia, no que tange aos partidos políticos, não estabelece qualquer limite para a fragmentação da representação. De igual modo, não exige que o cidadão tenha efetivo vínculo partidário com a agremiação, impondo apenas um ano de filiação para que este possa candidatar-se à um cargo público. Essa flacidez ideológica permite que o candidato eleito adote qualquer postura, qualquer prioridade e qualquer viés ideológico na tomada das decisões, descolando-se do ideário partidário e, assim, daqueles valores éticos e morais que permeiam a agremiação e, de resto, a sociedade.

0 sistema brasileiro também não exige vínculos profundos do candidato com a comunidade que vai representar, pois a lei determina que qualquer um com um ano de domicílio eleitoral pode candidatar-se. 0 próprio conceito de domicílio eleitoral favorece o divórcio com a sociedade, na medida em que o cidadão sequer precisa morar no município para representá-lo quer no executivo quer no legislativo.

O conceito de eleição proporcional para as assembléias legislativas dos municípios, estados e da União incita à separação do candida- 
to de sua comunidade, pois o vereador é eleito para ver os interesses de todos os bairros e distritos que compõem o município; os deputados estaduais pedem votos em todo o estado-membro, mesmo que não tenham qualquer vinculação com a maioria dos municípios que o compõem e sempre acabam sendo representantes, na prática, do sul, do sudeste ou do norte de seu estado, elegendo-se praticamente num distrito eleitoral que pretenderão beneficiar em detrimento daquelas outras regiões que lhes renderam poucos votos. 0 mesmo se dá com os deputados federais que acabam, por meio das emendas ao orçamento da União, atuando como vereadores deslocados pedindo verbas somente para aquelas regiões de seus estados-membros onde foram mais votados, numa fidelização do voto por dinheiro e obras e não, como deveria ser, na tomada das decisões políticas.

A prestação das contas de campanha é tratada como tabu, com a legislação impedindo que se acompanhe, durante a campanha eleitoral, quais os doadores dos candidatos, não permitindo, por parte dos eleitores a necessária crítica de quem financia cada um e, portanto, a provável fidelidade a quais interesses: aos do eleitor ou aos do financiador.

De outra parte, uma discussão já superada desde a Idade Média, conforme vimos acima, permanece sem solução definitiva no sistema brasileiro que é a questão de a quem pertence o mandato, se ao partido político ou ao candidato.

Ora, como vimos no item 2.2, é pacífico na doutrina há séculos que o povo não abre mão de seu poder ao conceder um mandato. 0 mandatário, ainda que seja um príncipe, não é o dono do poder, posto que este remanesce com o povo.

Enfim, outros defeitos se poderia apontar no sistema brasileiro, mas estes que vimos de indigitar são aqueles que, em nosso entender, deslegitimam o sistema brasileiro, permitindo com a contumácia de decisões políticas tomadas ao arrepio do sentimento ético e moral da maioria da sociedade. 


\section{CONCLUSÃo}

Por todo o expendido, parece-nos que o sistema brasileiro padece de tantas críticas e desconfianças porque permite a eleição de representantes sem qualquer vínculo ideológico com os partidos pelos quais se elegem e, por conseguinte, com a parcela da sociedade que comunga do mesmo ideário do partido; sem vínculos ou com vínculos muito tênues com o seu domicílio eleitoral, haja vista que este está conceituado de forma a permitir que as mais frágeis ligações dos candidatos com as comunidades que os elegem; permite eleger representantes sem saber exatamente quem os apóia financeiramente, pois este apoio tende a ser mais apto à garantir a fidelidade do candidato do que o simples voto depositado, já que, no mais das vezes, o eleitor não sabe o que pensa e como age o político e nem este sabe que é seu eleitor; permite que o representante trate seu capital de votos como próprio, entendo-se como dono de parte da soberania popular ao não estipular estrita fidelidade ao ideário partidário; e permite a excessiva fragmentação partidária com representação nas assembléias legislativas.

Constatadas as imperfeições do sistema, não podemos olvidar que essas imperfeições beneficiam os hoje representantes do povo que detém o poder para tomar a decisão política de rever o sistema e melhorá-lo.

Por isso, seria ingenuidade pensar que os jogadores do jogo político nacional, com as relevantes e minoritárias exceções de sempre, queiram alterar as regras que os beneficiam e que, por outro lado, os mantém do lado oposto ao da sociedade. Defendendo e aprovando normas jurídicas em contraste com os valores éticos dessa sociedade que os elege, os atuais representantes descolam-se do sentimento ético da Nação.

Em razão disso, é de mister, imprescindível mesmo, que a sociedade brasileira, lançando mão dos mecanismos de democracia direta que a Constituição do Brasil lhe garante, tome a iniciativa e desen- 
cadeie esse processo de reforma do sistema eleitoral como primeiro passo para uma reforma política profunda, que venha emprestar legitimidade aos seus representantes.

Esse primeiro passo deveria visar, segundo entendemos pelo menos um ou alguns dos seguintes pontos em ordem de importância.

a) Fidelidade Partidária estrita: seria exigência para a candidatura a qualquer cargo político a filiação por um período mínimo de quatro anos a determinado partido. Essa iniciativa teria dois efeitos benéficos: imporia a necessidade de intensa vida partidária ao cidadão e propiciaria seu ingresso na vida partidária bem cedo de modo a ascender dentro da agremiação; exigência de acompanhar as decisões partidárias nas tomadas de decisões políticas, aceitando-se a divergência se esta conflitar com o estatuto partidário;

b) Domicílio Eleitoral: o conceito de domicílio eleitoral, para o candidato ao cargo público deve ser estrito, com, no mínimo, quatro anos de domicílio e residência na circunscrição eleitoral pela qual pretender se eleger.

c) Adoção de distritos eleitorais: os vereadores deveriam ser eleitos por voto distrital, cujo distrito englobasse um ou dois bairros ou distritos municipais; os deputados estaduais e federais deveriam ser eleitos em circunscrições menores que o estado-membro, permitindo ao candidato se identificar mais com o eleitor e diminuindo os custos de campanha;

d) Contas de Campanha: total transparência das contas de campanha com a publicação mensal na rede mundial de computadores de todas as doações recebidas com identificação do nome dos doadores; e finalmente, 
e) Cláusula de Barreira: é livre a organização partidária, mas o partido só terá direito a assento no parlamento se atingir um mínimo de representatividade eleitoral em todo o País. Ainda que tal medida acabe por alijar siglas históricas no Brasil, permitir a fragmentação da representação partidária é um malefício muito maior às instituições do que a exclusão temporária dessas siglas do quadro de representação no parlamento.

É claro que estas propostas não reúnem uma unanimidade no campo doutrinário, nem foi esse o escopo do presente artigo. Com ele quisemos dar nossa contribuição para a discussão do tema e para que o improvável leitor possa melhor se posicionar a respeito desse tema que hoje perpassa completamente a idéia de País que queremos ter no futuro.

\section{REFERÊNCIAS BIBLIOGRÁFICAS}

Bobbio, Norberto; Matteucci, Nicola; e Pasquino, Gianfranco. Dicionário de Política, Editora Universidade de Brasília, Brasília, $12^{a}$ edição, 2004.

Cândido, Joel J. Direito Eleitoral Brasileiro, Editora Edipro, São Paulo, 11ª edição, 2004.

Gomes, José Jairo. Direito Eleitoral, Editora Del Rey, Belo Horizonte, 2008.

Mendes, Gilmar Ferreira; Coelho, Inocêncio Mártires; e Branco, Paulo Gustavo Gonet. Curso de Direito Constitucional, Editora Saraiva, São Paulo, 2007.

Morais, Carlos Blanco de. Democracia e Consenso na Decisão de Legislar, in Revista Brasileira de Direito Constitucional no 3, Jan. e Jun./2004, Editora Método, São Paulo. 
Pedra, Adriano Sant'Ana. Reforma Política: Compromissos e Desafios na Democracia Brasileira, in Arquivos de Direito Público: as transformações do Estado brasileiro e as novas perspectivas para o direito público / Adriano Sant'Ana Organizador, Editora Método, São Paulo, 2007.

A Constituição Viva, Editora Mandamentos, Belo Horizonte, 2005.

Silva, José Afonso da. Curso de Direito Constitucional Positivo, Editora Malheiros, São Paulo, 19ª edição, 2001.

Rocha, Maria Elizabeth Guimarães Teixeira. Democracia, Direito e Legitimidade. A crise do sistema representativo contemporâneo e os novos desafios do contrato social, in Revista Brasileira de Direito Constitucional, vol. I, Editora Escola Superior de Direito Constitucional, 2006. 